\title{
Information Systems Students as Independent Investigators of Truth
}

\author{
Saba Rahimi, Elsje Scott \\ University of Cape Town, South Africa
}

\begin{abstract}
In contrast to established fields, such as accounting or medicine, where curricula are relatively standardized, Information Systems curriculum has traditionally been slow to respond to industry needs, generic in nature and has served as a guideline rather than an authoritative truth. This is amplified by the field constantly engaging in debates about its intellectual boundaries, identity and core focus. This debate has perpetuated as the field constantly changes its identity in response to rapid and often turbulent technological advances. This vastness causes inconsistent focus and different prioritization across geographic regions, academic institutions and industry entities. This research is concerned with how the nature of the field affects Information Systems students and graduates, and seeks to investigate how students can contend both with the vastness of the subject matter and the lack of authoritarian guidelines. The existential characteristic of psychological ownership and a desire to independently investigate the truth is presented as a possible philosophy that can be instilled in students to help them contend with the nature of the field.
\end{abstract}

\section{Introduction}

There are different perceptions to which one is exposed when examining literature about the history and origins of the Information Systems (IS) field. Hart [22] stated that the IS field was established because advancements in computing technology meant that computers and processing of data became more integrated and useful as tools in business disciplines. Whilst some concur with this perspective, some observe that the field has a lack of history as it discards its identity in line with technological advancement and new technological capabilities [24]. This lack of history and change in identity has caused ongoing debate about the definition of the field as well as inconsistent perspectives as to what constitutes its central focus $[5,9,24,28]$. These debates have been persistent since the field's inception [28] and have resulted in the consensus that diversity is a defining characteristic of the field [2]. There has been an abundance of research arguing that academia has a difficult time, in keeping up with the rate of technological change [32] thereby creating a gap between graduate skills and industry needs [25]. Whilst literature identifies gaps between academic output and industry needs [5, 21, 24], there is limited research into how students have or should overcome the challenge of moving out of academia into industry. Our previous focus when reporting on this research was presented at IIEC 2015 titled The Existential Journey for Information Systems Students was concerned with the needs of IS students. How they develop in university and how, by overcoming the gap between academia and industry, they can become effective practitioners in industry. A framework identifying the existential characteristics of Psychological Ownership, being exposed to Reality and Reflection was presented as crucial tools in contending with the nature of the field. This paper focuses more specifically on the element of Psychological Ownership and provides a deeper analysis on its value and importance in creating students who can contend with the lack of truth in the field; creating students who are independent investigators of truth. Such students could be thought of those who, by possessing the existential characteristic of Psychological Ownership, take responsibility for learning and strive to be selfreflective and self-corrective, seeking to advance and grow in ways that are autonomous, self-sustained and self-governed [5]. In this endeavor the learner will form an identity based on their own experiences of different perspectives in the field.

\section{Challenges in Academia}

In examining the unique nature of the field it is important to examine the challenges faced by the academic entities in the field. Three such challenges were identified.

\subsection{Existence and Enrollment Crisis}

The IS field is comprised by many constituent parts with conflicting fluid ideologies. This lack of a core identity is demonstrated and compounded by a vast array of names, 21, with which IS departments identify themselves [40]. The identity crisis, leads to difficulty for academic departments to draw comparisons with each other thereby causing 
universities to question the need for IS departments and Deans holding the 'disturbing belief' that the field is losing relevance [24]. It is highlighted that some IS-related subjects were combined with other subjects such as marketing and e-business [39]. There is evidence that the identity crisis in the field and a lack of understanding of its nature have caused enrolments in IS courses to decline [24] and the relevance of IS courses to be brought into question [10]. March and Niederman [33] suggest that the identity crisis, the lack of standardization and uncertainty about the future or nature of the field can lead to students being hesitant to enroll.

\subsection{Keeping up with Industry Needs}

While there are many research-led universities, it is reasonable to expect that students expect "their degrees to qualify them for a career in the discipline" [4]. If one holds the view that academic institutions exist to prepare students for industry a difficult challenge is placed on academic institutions and learners, not only in needing to be agile in keeping up with current technological trends and industry needs [25], but in deciding which technological trends and industry needs to keep up with. Educators need to therefore constantly correct and adapt to changing needs of the employers in industry [25]. In order to contend with the rapidly changing needs, there are those who believe that links to industry are essential in meeting real-world demands. Some feel that joint ventures, between academia and industry are critical in facilitating some form of cohesion between theory and practice [31]. Others, identify a disconnection between academic research and its use in industry [23] and argue a persistent "gap between what industry wants characteristically in IS personnel and what academia provides them" [21].

\subsection{Differentiated Curriculum}

The accounting field provides a good contrast to IS in terms of curriculum development and delivery. Whilst the identity of the Information Systems field is debated, the accounting field which is firmly established, is governed by regulation bodies and GAAP. These provide an audited and legally regulated basis for firms and practitioners to operate with and refer to. In contrast the dynamic and complex environment of the IS field means that "no single IS curriculum can possibly achieve all of industry's requirements" [21]. A “one-size-fits-all" or a "one-size-fits-most" approach is not appropriate. Technological advances require IS curricula to be constantly re-evaluated [39]. The IS field does not have the luxury of authoritarian bodies or figures, but rather contains an eclectic collective of associations and journals which provide guidelines on curriculum development and application. Dahlbom [9] identified four eras in the history of the field in which hardware capabilities evolved and the field therefore changed focus. Hirschheim and Klein [24] identified each of the phases as a "discarding of an identity in search of another." If one were to hold the view that curricula should be adaptive and responsive to changes in industry needs and technological capabilities, one could argue that the fact that only three revisions to IS curriculum have been produced in the last two decades, is inadequate. IS2010 is the latest curriculum developed by the Association for Computing Machinery (ACM) and the Association for Information Systems (AIS). It is the first and last major revision to IS curriculum guidelines since 2002. The IS2010 curriculum guidelines document acknowledges that its predecessor, IS2002 focused too narrowly on the business domain and acknowledges that there is an inability to apply IS curriculum globally and consistently. IS2010 encourages the use of elective subjects to guide application to as many possible relevant domains. This implies that the focus of the field is becoming wider and the potential for more identity issues is increasing. The guidelines appear to have become less regulated leaving more room for academic institutions to interpret and apply curriculum diversely and inconsistently. In addition to the narrow focus on the business domain, the IS2010 guidelines also acknowledge another shortfall of its predecessor; that traditional curriculum development has been too narrowly focused on North American business schools, and that flexibility of curriculum is necessary to allow for application and adoption of guidelines into differing educational contexts. While many see IT as a 'Great Globaliser,' "IT education has not converged to some worldwide standard" [16]. In addition to there being a difference in the developing and developed world, it is suggested that universities should consider the regional area as well as the institutional objectives in structuring curriculum [4].

A very clear example of differing curricula between the developing and developed world, in comparing the curriculum applied in India with that applied in the United States of America. The United States of America can be identified as being more liberal and more focused on social factors and social issues around IS. Factors such as assurance, security and human computer interaction, were more prominent in the American curriculum. These same factors were non-existent in the Indian IT curriculum, which was more focuses on technical factors such as mathematics and thermodynamics, for example [16]. 


\section{Possible effects on Students}

The challenged faced by Academia may cause potential challenges for a student. Literature was examined and three such challenges were identified.

\subsection{Enrollment Hesitation or Anxiety}

Should a student wish to study IS, the task of choosing a university would be complicated due to inconsistencies in interpretation and application of curricula and the choice of electives. This could have far-reaching consequences in shaping potential career paths. At this level students are not necessarily equipped to interpret the conflicting ideologies within the field and make value judgements.

\subsection{Choosing a Role}

In addition to universities taking differing approaches and placing emphasis/focus on different areas, many relevant roles and factors become apparent. Four categories of skills relevant to the IS field: 'Soft', 'Business', 'Technical' and 'Green' can be identified. The latter being unique to the study and concerned with the sustainability of IT and an awareness of its effects on the environment [37]. These categories contained a total of 84 different skills relevant to the field. With such a wide area of intellectual territory, the field is regarded as "one of the most dynamic fields that has ever existed" [7]. This means that career paths are no longer predictable and would require different knowledge and skills as their careers progress [32]. In contrast to the accounting and medical fields, the IS student has the pressure of making potentially career defining decisions about specialization during or even before the start of their undergraduate studies. These decisions are often uninformed.

\subsection{A lack of truth}

The results of these differing applications, areas of focus and ideologies in the field could lead one to argue that the field does not contain any ultimate truth. Curricula guidelines are applied differently in differing environments with there being a need for academic institutions to apply institutional, regional objectives and political and legal needs in structuring curricula [4]. In developing IS2002 it was stated that their model curriculum should "guide but not prescribe" [20]. Curricula must "adapt to its own needs, circumstances and characteristics" and it must "reflect the needs of the community it directly serves" [4]. In addition, it must cater for a "dominant technology, industry or employer" by tailoring curricula for that environment [4]. Whilst it is possible to create awareness of different perspectives or areas of focus, it is unlikely that any academic institution could possibly coherently cover all areas and roles to a sufficient level of depth, and therefore would prioritize and guide the learner towards a subjective standard. Propagating "best practices" or "one best way" is almost criminal [8]. The IS field is thus one that is not ruled by one truth, but is rather characterized by practitioners independently embarking on a search for finding the truth for a particular situation. Knowledge is perspectival and that any theories of reality or truth are "organically embedded in our culture and hence conditioned by our point of view" [35]. Should students be guided to a subjective standard (which is a form of limited truth) based on the ideologies and priorities of a single academic institution, there would be differing subjective standards that define IS competency and therefore a lack of truth in defining competency. Accounting students, for example, who would be entering an industry governed by established best practices and regulation bodies, the IS student will be learning a standard or best practice relevant to a certain institution or area. These students will be operating in completely different psychological mind sets by having to establish their own truth based on circumstance. It can be generally accepted that effective learning must be self-directed, selfinternalized and self-monitored [1]. Traditional education in which a generic student was viewed as a recipient, like a jug, into which knowledge and facts were poured, is inoperable. IS practitioners need to acquire lifelong learning skills in order to contend with the messy, nonlinear and ill-defined problems that are the hallmark of changing workplace demands [30]. IS learners must be self-reflective and self-corrective seeking to advance and grow in ways that are autonomous, self-sustained and selfgoverned [5]. An attitude of existentialism or lifelong learning is similar to the attitude of 'autodidaxy,' which can be described as the ability to teach oneself by having a sense of personal control in one's learning by "creating a climate of self-direction and inquiry" [6], could be considered a valuable attribute to contend with the nature of the IS field.

\section{The Value of Existentialism}

From the previous section it is clear that the challenges faced by academia and students lead to their being a lack of IS truth. It is argued that an attitude of existentialism is necessary to contend with the nature of the field.

\subsection{Defining Existentialism}

The existential characteristic can be attributed to people who have their attention directed towards their own nature [19]. They will recognize that their talents, inclinations and passions are within their 
power to cultivate. They take responsibility for themselves rather than treating their nature as unalterable. This involves development of selfknowledge beyond mere contemplation, and rather reflecting on oneself. Those with a strong sense of existentialism consider themselves as independent entities who look inward for ultimate responsibility and accountability. They recognize the value of individuality and through interaction, reflection and action based on their own standards and wills, seek to advance.

\subsection{The Existential Path}

The existential characteristic is essential in contending with the lack of truth and the multitude of ideologies in the field. Rather than allowing an external factor, such as the ideology of a single institution, region or company; to shape them, existential IS learners must direct their attention to their own nature and seek to explore the complexities of the field and align their efforts and interests with constituencies that share their standards and wills. The characteristic of existentialism causes a person to throw themselves into an activity with "passionate involvement" [12]. The learner is no longer satisfied with being a passive recipient of information, but rather seeks to break that information down for serious purposes, through conscious and deliberate alignment to certain perspectives and with commitment to involved action [12]. This involves the learner taking the initiative to learn for "one's own sake" or one's "own account for the sake of the satisfaction it yields" [41]. Through making commitments and seeing perspectives the learner will be able to distinguish the relevance of various sources of information. In addition, the commitment to a certain perspective may allow the learner to feel a sense of identity based on the commitments they have made.

Such initiatives will require motivation as it is "unlikely that students will immediately or without provocation assume responsibility for the learning environment. The commitment of apprenticeship will enable learners to feed off an expert's "vast repertoire of situational discriminations" [11]. There is a need to work under different experts in order to avoid cloning and to help the learner move out into mastery and develop their own sense of style [11]. Rather than becoming an advocate for a single truth, the learner will gain an understanding of the true nature of IS thereby recognizing the relativity and fluidity of IS truth. The learner would make a commitment to the adventurous journey in a field where there is an ever-pressing need to independently investigate the truth with a subjective interpretive approach to dynamically defining truth for a particular circumstance.

\section{Crucial Existential Characteristics}

The concept of existentialism, as a means of contending with the lack of truth in the field, is generic and abstract. Three explicit existential characteristics of Psychological Ownership, a need for Reality and a need for Reflection can be identified and used as a framework [36]. Each element of the framework is presented followed by an overview. The element of Psychological Ownership is then discussed further.

\subsection{The Elements}

Psychological Ownership can be described as learners the act of taking ownership of one development by self-driven actions [36]. Whilst there is need for one to be self-driven it can be argued that actions are rarely effective in solitude and must arise from a real situation [36]. Therefore a need for Reality, and being involved in real situations, results in learners being more in touch with their feelings and more aware of the limitations of their abilities [36]. In addition a third element, that of Reflection, can be defined as the action of critically analyzing one's past experiences and adjusting one's identity and approach to problems for future tasks [36].

\subsection{The Framework}

Figure 1 demonstrates that there is a cyclical relationship between Psychological Ownership, Reality and Reflection. Learners taking Psychological Ownership over their development could serve as provocation to move out of a passive mindset. This Psychological Ownership can be "instilled by" having real projects and real consequences [6, 35]. Having Psychological Ownership of one's development can lead to learners gaining a desire to seek, or "create desire for" real circumstances and consequences, thereby forcing the learner out of their comfort zones and searching for situations from which to learn themselves out [26, 35]

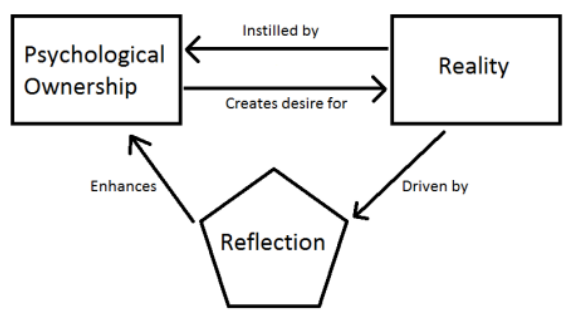

Figure 1. Own, Do and Reflect

In addition to the relationship between Psychological Ownership and Reality, by having had real experiences, the learner would have been emotionally involved in the task and would therefore 
have felt the elation of success as well as the disappointment of failure. The result of such interactions and emotions would lead to the learner having the reservoir, or arsenal, of past experiences necessary to reflect on and help them grow. The act of Reflection is "driven by" the learner having had real experiences [26]. In addition, it was argued that the act of Reflection can "enhance" Psychological Ownership by allowing the learner to critically reflect on the different experiences they may have had and avoid being transfixed on a particular perspective or view [35]. Having experiences results in material to reflect on, which then enhances the learner's Psychological Ownership and creates more desire for real experiences. In practical terms, this is the process a learner may face, doing multiple projects, in an existential journey through an academic institution. The university could 'provoke' learners by making them choose and commit to a real social context. The cyclical relationship between these existential categories was confirmed by analysis of the relationship between the categories. All respondents referenced the "provocation" of their third and fourth year projects as central to their development. As a result of the real nature of the project, the learners took ownership and developed themselves. One respondent, in describing the move from third year to fourth year, supported the notion that having completed the project gave the learners material to reflect on by being able to inspect and adapt and gain an understanding of one's ability by understanding where the pain points are going to be. Through being honest enough with yourself and being retrospective in admission of areas of failure, one builds actions that prevent themselves from repeating mistakes in the future. By being exposed to the real consequences of the third-year project, the learners experienced emotions and feelings that lead to their taking ownership by being honest enough with themselves, being retrospective through reflection, and changing their approach in the second experience. Reflecting on a real experience was identified as a huge part in honing skills because it allowed one to learn from your mistakes and from other people's mistakes. Through this reflection and discussion with other people one reflects and adjusts their approach by finding out what would they do differently next time by taking advice, and ensuring that in a different situation mistakes are not repeated. In addition, it was argued that being exposed to real situations and taking ownership, one recognizes the need to reflect and change with each project that comes along.

\subsection{Psychological Ownership}

The existential characteristic of psychological ownership can be described as a learner taking responsibility for their learning and seeking to apply knowledge to personally relevant problems [14]. Learners must move away from a mind-set that they are "empty vessels" [35] or metaphorical jugs, or recipients who need to be filled with knowledge [1]. Rather, literature calls for learners to be selfreflective and self-corrective, seeking to advance and grow in ways that are autonomous, selfsustained and self-governed [5]. This would involve their taking ownership or control of their own learning endeavor and seeking an independent, selfmotivated journey of development [6]. Jordi [26] speaks of "intentional" actions that would result in "stretching" one's own experiences forward. This involves learners being autonomous, reliable in their sense of self awareness, and being more inclined to accept their actions as their own responsibilities [35]. Such intentional actions could involve putting oneself in work situations where learning that is "a by-product of some other activity, and may happen unconsciously or incidentally" [13] can occur. In the presence of a lack of globally applicable curriculum, many authors stress the need for learners to make commitments to certain real-world situations [22, 39]. Furthermore, it is argued that a learner-centered or learner-driven approach will result in more engagement with the material [15]. In these approaches learners will seek to "make sense of ideas for themselves", thereby allowing learners to shape an understanding based around transforming information into "personal meaning" based on their own talents, inclinations and wills [12]. This is essential as "learning approaches are not set traits, but are chosen anew for every task" [18]. Upon testing this theory, students who were accustomed to independent learning provided more strategic solutions when faced with problems [15]. Transparent collaboration, rather than authoritarian dictation, in apprenticeships can lead to learners taking responsibility for themselves [34].

\section{Research Design}

\subsection{Research Purpose}

The purpose of this research is to examine the experiences of Alumni and their journey from undergraduate students to practitioners in industry. In doing so, interventions that helped them in their development can be identified which could lead to further insight into how students can be equipped to contend with the challenges of the field. In this endeavor the theoretical framework (of psychological ownership, reality and reflection) was tested in order to gain insight into how best to equip learners to perform well in academia and subsequently make a smooth transition to industry. Having presented this research the researchers sought to further discuss the importance of 
Psychological Ownership in contending with the nature of the field.

\subsection{Research Sample and Philosophy}

The interpretive philosophy is often associated with case study research. Interpretive philosophy is described as a philosophy which values analysis of unique circumstances and is highly suspicious of any claim that studies of human behavior can be culturally independent [29]. Therefore each instance of interpretive research can be treated as a "unique historical occurrence" [29]. This research could be considered a "unique historical occurrence" as it is a case study limited to a qualitative analysis of the reflective accounts (expressed in semi-structured interviews and e-mail questionnaires) of the experiences of IS graduates from the University of Cape Town and Graduate Recruitment Officers. For ethical reasons the caliber (i.e. factors such as the historical academic performance, role in industry or perceived success) of participants was not screened and no willing interviewees were excluded from the sample. It also examines the accounts of Graduate Recruitment Officers who have over two years' experience in hiring graduates. Although this study encompasses 5 years of graduates (44 in total), the data collection was conducted in 2012 and in 2014. It sought to gain insight from practitioners with differing levels of experiences and exposure to industry, as well as from those Graduate Recruitment Officers (six in total) responsible for hiring them. Therefore the study can be thought of as crosssectional as opposed to longitudinal.

\subsection{Data Treatment}

After the interviews were conducted, the audio files were personally transcribed and proof read by the researcher in order to allow for deeper understanding and reflection on the accounts of the Alumni. Responses were organized and coded by their relevance to elements of the theoretical framework induced from literature. The combination of both graduates and Graduate Recruitment Officers, provided another perspective, an engaging observer's perspective on graduate readiness and adaptation to industry. In analyzing the data generated from the interviews, the researcher used deductive analysis. A thematic analysis was conducted as the data was qualitative and an interpretive philosophy was used. Successful confirmation of the theory would involve graduates expressing existential interventions as being central tools in their development.

\section{Findings}

Having completed the interviews and the deductive analysis, the researchers found evidence to support the existential framework presented in section 5. The findings for the element of Psychological Ownership is now discussed.

\subsection{The Existential Path}

In analyzing the results, support for psychological ownership could be identified by students expressing the need for them to take ownership of their development. The key words identified were 'Self,' 'Improve,' 'Investigate' and 'Jump In.' Of the 44 respondents, 32 (72.73\%), made 44 statements that highlighted Psychological Ownership as a necessary characteristic in their development. The most explicit indication of a link between Psychological Ownership and effective learning can be found where the respondent described a responsibility as sort of my baby and indicated that she had learned a lot through that. Echoing this sentiment, one respondent stated that being given responsibility made him feel important and that lead to his willingness to put in extra effort. The responses indicated that self-learning is a core value necessary for development of competence. This concurs with the sentiment [26] that learning should be intentional and attempt at stretching one's experiences forward. In essence you can talk about it as much as you want but unless a learner takes the initiative to actually go and intentionally place themselves in situations that stretch their experiences. A learner needs to have that personality trait, that characteristic of being willing to also work on things and investigate and work things out. Many respondents highlighted their third-year project as a defining moment as it was the first instance where the project was owned by the student. Some described this as a great experience as they were creating something for themselves. The students felt that doing the whole thing from scratch and doing it all ourselves was the main thing that shaped their careers. The unstructured nature of the project meant that learners had to unleash the power of unstructured and creative thinking and that there isn't a written solution which required their having to work things out and fend for themselves. Part of this experience involves deciding on which area to focus on and many argued that people function better when they are working on their passions as opposed to just being made to work on things that they are seen as good at. A student concurred with this sentiment very sternly. His passion for cycling, allowed him to create and own a cycling website. He regarded this as a key experience in his development. The evidence from the Graduate Recruitment Officer accounts concurs with the perspective that having 
autonomy and freedom to manage one's own work results in people becoming more excited to work on their own material. One respondent argued it was part of human nature to be more excited about one's own ideas. Of the six companies approached, all offered ownership of work to employees (four formally) and indicated that this helped with motivation. Two companies went further and indicated that work done in free time and driven by an employee initiative, resulted in useful application as the work would go into production.

\subsection{Differentiated Curriculum}

As discussed in sections 2 and 3, the nature of the field and its lack of truth causes difficulty in Academia keeping up with industry needs and the need to have differentiated curriculum that considers regional and institutional needs and objectives. The findings indicated that learners grew by moving beyond curriculum. One student remarked that if we had not gone out and taught ourselves what we had needed for our project, we would not have been in any way qualified to start in industry. There was support for the notion that taking psychological ownership by having to go out, find a client, someone to work for, getting business requirements from them resulted in learners prioritizing elements they felt were personally relevant. Curriculum serving as guidelines rather than prescribe best practices and having reduced facilitation, identified as crucial to deep learning [18], led to learners having to mostly self-teach themselves through a huge learning curve. This sentiment carried through to industry where the need to learn to manage one's self was emphasized. In support of this sentiment, findings from the Graduate Recruitment Officers indicated that graduates were rarely self-starters and needed direction; but they asked to be thrown in the deep end and tended to respond well to this and felt held back when they were not in control of their development. Although in the interviews there were evidences of respondents blaming circumstance and external factors for some of their failures when asked about reflection, all respondents felt the need to adjust their own approaches and question their own assumptions. The responses contained 49, 35 and 23 counts of the pronouns "I", "you" and "we" respectively. In addition, only four of the responses contained reflective practices being triggered from external sources, such as SCRUM, feedback meetings, peer reviews or performance appraisals. This indicates support for the notion that one requires psychological ownership to recognize that reflection is one's own responsibility. This results in their desire to inspect and adapt and ponder what did I do wrong, what did I do right? Thereby adjusting their approaches in order to give a richer understanding of what is necessary.

\section{Conclusion}

This research paper discussed the challenges the nature of the IS field may place on IS students. As emphasized: real-world problems "do not present themselves as givens" [38]. The fluid, ever changing and diverse nature of the IS field has been a defining characteristic throughout its history. Perhaps, in seeking to participate in this field, one should not seek a standard and blindly conform to it. Rather, those who seek to become IS practitioners should take Psychological Ownership by making a commitment, with bold intellectual reach [27], to independently investigating the truth of each circumstance thereby partaking in an adventurous journey of growing with the IS field. One should seek a "climate of self-direction and inquiry" [6], thereby making a commitment to arm oneself with the existential characteristics necessary to change oneself, through inspecting and adapting to different circumstances and different conditions. Each situation would involve a subjective interpretive approach to dynamically defining truth and represent milestones on an existential journey toward competence. Ample evidence was presented to suggest that students took more interest in studies when the work they were required to complete had personal relevance. Ample evidence, was presented to suggest that learners needed to take Psychological Ownership by taking intentional actions to place themselves in situations where they would move beyond curriculum guidelines.

\section{References}

[1] Aspin, D. N. \& Chapman, J. D. (2012). Towards a Philosophy of Lifelong Learning. In Second International Handbook of Lifelong Learning (pp. 3-35). Springer Netherlands, 26(1), p3-35.

[2] Banville, C. \& Landry, M. (1989). Can the Field of MIS be Disciplined ? Communications of the ACM, 32(1), 48-60.

[3] Braun, G. F., Tesch, D. \& Colton, D. (2005). The Student-Professor Research Relationship: Examining IS Employer Skills Expectations. Information Systems Education Journal, 3(42), 1-12.

[4] Brewer, J., Harriger, A. \& Mendonca, J. (2006). Beyond the Model : Building an Effective and Dynamic IT Curriculum. Journal of Information Technology Education, 5(1), 441-458.

[5] Bryant, A. \& Land, F. (2012). Discursive Formations and Trans-Disciplinary Agendas: A Response to Walsham. Journal of Information Technology, 27(3), 249-254.

[6] Candy, P. C. (1991). Self-Direction for Lifelong Learning: A Comprehensive Guide to Theory and Practice. San Francisco, CA, USA: Jossey-Bass. 
[7] Cappel, J. (2001, 3-5 August). Skills of Information Systems Graduates: An Exploratory Study. Paper presented at the 7th Americas Conference on Information Systems (pp. 1932-1935). Boston, MA, USA.

[8] Crawford, L., Morris, P., Thomas, J. \& Winter, M. (2006). Practitioner development: From Trained Technicians to Reflective Practitioners. International Journal of Project Management, 24(8), 722-733.

[9] Dahlbom, B. (1996). The New Informatics. Scandinavian Journal of Information Systems, 8(2), 29-48.

[10] Davidson, E. J. (2011). "Hey professor, why are you teaching this class?" Reflections on the relevance of IS research for undergraduate students. European Journal of Information Systems, 20(2), 133-138.

[11] Dreyfus, H. (2001). How Far Is Distance Learning From Education? Bulletin of Science, Technology \& Society, 21(3), 165-174.

[12] Dreyfus, H. L. (1999). Anonymity versus Commitment: The Dangers of Education on the Internet. Ethics and Information Technology, 1(1), 15-21.

[13] Druskat, V. U. \& Pescosolido, A. T. (2002). The Content of Effective Teamwork Mental Models in Selfmanaging Teams: Ownership, learning and heedful interrelating. Human Relations, 55(3), 283-314.

[14] Entwistle, N. (2000, November). Promoting Deep Learning Through Teaching and Assessment: Conceptual Frameworks and Educational Contexts. In TLRP Conference (pp. 1-12). Leicester, UK.

[15] Entwistle, N. J. \& Peterson, E. R. (2004). Conceptions of Learning and Knowledge in Higher Education: Relationships with Study Behaviour and Influences of Learning Environments. International Journal of Educational Research, 41(6), 407-428.

[16] Ezer, J. (2006). India and the USA : A Comparison through the Lens of Model IT Curricula. Journal of Information Technology Education, 5(1), 429-440.

[17] Frith-Cozens, J. (2001). Cultures for Improving Patient Safety Through Learning: The Role of Teamwork. Quality in Health Care, 10 (suppl 2), ii26-ii31.

[18] Froehlich, D., Segers, M. \& Van Den Bossche, P. (2014). Informal Workplace Learning in Austrian Banks : The Influence of Learning Approach, Leadership Style, and Organizational Learning Culture on Managers' Learning Outcomes. Human Resource Development Quarterly, 25(1), 29-57.

[19] Gardiner, P. (1988). Kierkegaard: A very short introduction. Oxford University Press.

[20] Gargone, J. T., Davis, G. B., Valacich, J. S., Topi, H., Feinstein, D. L. \& Longenecker, H.E. Jr. (2002). IS 2002 Model Curriculum and Guidelines for Undergraduate Degree Programs in Information Systems. Communications of the Association for Information Systems, 11(1), 1 .
[21] Gupta, J. N. D. \& Wachter, R. M. (1998). A Capstone Course in the Information Systems Curriculum. International Journal of Information Management, 18(6), 427-441.

[22] Hart, M. (2006). The Information Technology Model Curriculum. Journal of Information Technology Education, $5,338-342$.

[23] Hevner, A. R., March, S. T., Park, J. \& Ram, S. (2004). Design Science in Information Systems Research. MIS Quarterly, 28(1), 75-105.

[24] Hirschheim, R. \& Klein, H. K. (2003). Crisis in the IS Field? A Critical Reflection on the State of the Discipline. Journal of the Association for Information Systems, 4(5), 237-293.

[25] Janicki, T. N., Kline, D., Gowan, J. A. \& Konopaske, R. (2004). Matching Employer Needs With IS Curriculum: An Exploratory Study. Information Systems Education Journal, 2(21), 3.

[26] Jordi, R. (2010). Reframing the Concept of Reflection: Consciousness, Experiential Learning, and Reflective Learning Practices. Adult Education Quarterly, 61(2), 181-197.

[27] King, J. \& Lyytinen, K. (2003). When Grasp Exceeds Reach: Will Fortifying our Theoretical Core Save the Information Systems (IS) Field? People and Computers: Twenty-one Ways of Looking at Information Systems: Festschrift Celebratinge Markku Nurminen's 60th Birthday, ed. T. Jarvi and P. Reijonen, vol. TUCS General Publication, (26), pp. 143-166.

[28] Klein, H. K. \& Hirschheim, R. (2008). The Structure of the IS Discipline Reconsidered: Implications and Reflections from a Community of Practice Perspective. Information and Organization, 18(4), 280-302.

[29] Klein, H. K. \& Myers, M. D. (1999). A Set of Principles for Conducting and Evaluating Interpretive Field Studies in Information Systems. MIS Quarterly, 23(1), 67-93.

[30] Kroeze, J. H., Lotriet, H. H., Mavetera, N., Pfaff, M. S., Postma, D. J. v. R., Sewchurran, K. \& Topi, K. (2011). ECIS 2010 Panel Report: Humanities-Enriched Information Systems.

[31] Land, F., Loebbecke, C., Angehrn, A. A., Clemons, E. K., Hevner, A. R., \& Mueller, G. (2009). ICIS 2008 Panel Report: Design Science in Information Systems : Hegemony, Bandwagon, or New Wave ? Communications of the Association for Information Systems, 24(1), 501508 .

[32] Lee, S., Koh, S., Yen, D. \& Tang, H.-L. (2002). Perception Gaps Between IS academics and IS Practitioners: an Exploratory Study. Information \& Management, 40(1), 51-61.

[33] March, S. T. \& Niederman, F. (2012). The Future of the Information Systems Discipline: a Response to 
Walsham. Journal of Information Technology, 27(2), 9699.

[34] Moore, J. O., Marshall, M. A., Judge, D. C., Moss, F. H., Gilroy, S. J., Crocker, J. B. \& Zusman, R. M. (2014). Technology-Supported Apprenticeship in the Management of

Hypertension: A Randomized Controlled Trial. Journal of Clinical Outcomes Management, 21(3), 110-122.

[35] Raelin, J. A. (2007). Toward an Epistemology of Practice. Academy of Management, 6(4), 495-519.

[36] Rahimi, S. \& Scott, E. (2015). The Existential Journey of Information Systems Students. Proceedings of the Ireland International Conference on Education (IICE2015), Dublin, Ireland.

[37] Richards, D., Marrone, M. \& Vatanasakdakul, S. (2011, 30th November - 2nd December). What does an Information Systems Graduate need to know? A focus on Business Analysts and their role in sustainability. In 22nd Australasian Conference on Information Systems, Sydney, Australia.

[38] Schön, D. (1983). The Reflective Practitioner: How Professionals Think in Action (Vol. 5126). Basic Books.

[39] Tatnall, A. \& Burgess, S. (2009). Evolution of Information Systems Curriculum in an Australian University over the Last Twenty-Five Years. IFIP Advances in Information and Communication Technology, 302, 238-246.

[40] Topi, H., Valacich, J. S., Wright, R. T., Kaiser, K., Jay F. Nunamaker, J., Sipior, J. C., \& de Vreede, G.J. (2010). IS 2010: Curriculum Guidelines for Undergraduate Degree Programs in Information Systems. Communications of the Association for Information Systems, 26(1), 18.

[41] Williams, K. (2000). Beyond the Needs of Industry: the Liberal Dimension of a Technological Education. Pedagogy, Culture \& Society, 8(1), 85-92. 